\title{
Coronary Dissection due to Overdilatation of an Elastic Membrane of the Multi-Link Stent Delivery System Caused by Balloon Rupture
}

\author{
Nakabumi Kuroda, MD; Yoshio Kobayashi, MD; Joseph De Gregorio, MD*; \\ Takahiko Kinoshita, MD; Mizuo Nameki, MD; Yutaka Yamamoto, MD; \\ Akira Miyazaki, MD; Yoshiaki Masuda, MD
}

\begin{abstract}
A 65-year-old male with unstable angina underwent coronary angiography, which revealed a significant stenotic lesion in the right coronary artery. This narrowing was subsequently treated with the Multi-Link stent. During the balloon inflation associated with stent deployment, balloon rupture occurred and resulted in overdilatation of an elastic membrane in the stent delivery system. This, in turn, resulted in coronary dissection, which required treatment with further stenting. (Jpn Circ J 1999; 63: 912-913)
\end{abstract}

Key Words: Angioplasty; Coronary artery disease; Stent

$\mathbf{S}$ econd generation stents, such as the Multi-Link stent (Guidant, Santa Clara, CA, USA), represent a vast improvement in interventional technology and are currently the most commonly utilized stents. Recent trials involving the Multi-Link stent have demonstrated low rates of both angiographic restenosis and target lesion revascularization!,2 The delivery system for the Multi-Link stent contains an elastic membrane between the stent and the balloon catheter. We describe a case of coronary dissection caused by overdilatation of the elastic membrane due to balloon rupture in the Multi-Link stent delivery system.

\section{Case Report}

A 65-year-old male was admitted to hospital because of the recent onset unstable angina. Coronary angiography was performed and revealed a $90 \%$ stenosis in the proximal right coronary artery (RCA) (Fig 1A). The left anterior descending artery and the left circumflex artery were free of significant coronary artery disease. A 6F FR4 Cyber guiding catheter (SCIMED, Maple Grove, MN, USA) was positioned at the RCA ostium. A 0.014" Balance guidewire (Guidant) was advanced across the lesion into the distal lumen of the RCA. Initially, balloon angioplasty was performed using a $3.5 \mathrm{~mm}$ Maxxum balloon catheter (SCIMED) inflated to 6 atmospheres. Then, a $15-\mathrm{mm}$ Multi-Link stent, premounted on a $3.5 \mathrm{~mm}$ balloon catheter, was positioned at the lesion site (Fig 1B). While the balloon catheter was slowly being inflated, the balloon inflation pressure fell abruptly from 7 to 3 atmospheres. Coronary angiographic observation during inflation revealed overdilatation of the proximal portion of the balloon catheter (Fig 1C). Although the balloon catheter

(Received April 14, 1999; revised manuscript received August 6, 1999; accepted August 9, 1999)

The Third Department of Internal Medicine, Chiba University, Chiba, Japan and *St Michael's Medical Center, Newark, New Jersey, USA Mailing address: Yoshio Kobayashi, MD, The Third Department of Internal Medicine, Chiba University, 1-8-1 Inohana, Chuo-ku, Chibashi, Chiba 260-8670, Japan. E-mail: cum124t@med.m.chiba-u.ac.jp was deflated, the overdilatation remained. An attempt was made to remove the balloon catheter by pulling it back into the guiding catheter; however, this was unsuccessful. Subsequently, the guidewire, balloon catheter, and guiding catheter were withdrawn from the coronary artery as one assembled unit, leaving the stent in place. Coronary angiography revealed a coronary dissection with forward flow proximal to the Multi-Link stent (Fig 1D). An 18-mm gfx stent (Arterial Vascular Engineering, Santa Rosa, CA, USA) premounted on a $3.5-\mathrm{mm}$ balloon catheter was then deployed to treat this dissection (Fig 1E). Additional balloon inflations were performed in both the Multi-Link stent and the gfx stent with a $3.5 \mathrm{~mm}$ Maxxum balloon catheter reaching an inflation pressure of $16 \mathrm{~atm}$. The final angiogram demonstrated a good result (Fig 1F).

\section{Discussion}

Clinical and angiographic restenosis rates in selected lesions are reduced with coronary stenting compared with conventional balloon angioplasty? Sufficient radial strength to support the vessel and good flexibility to reach a target lesion are 2 of the most important features of an ideal coronary stent. However, the 'first generation' stents, such as the Palmaz-Schatz stent and the Gianturco-Roubin stent, have only one of those features. The Palmaz-Schatz stent has high radial force and low flexibility, whereas the Gianturco-Roubin stent has low radial strength and high flexibility. The second generation stents such as the MultiLink stent are now the most commonly used stents and represent significant advancements in stent technology. The Multi-Link stent demonstrates good flexibility prior to expansion despite lack of any articulation site. The structural design enables excellent support and scaffolding after deployment. Low restenosis rates and low target lesion revascularization rates with the Multi-Link stent have been demonstrated in recent studies 1,2

The Multi-Link stent delivery system contains an elastic membrane, called the C-Flex, which is located between the stent and balloon catheter. This silicone membrane has 

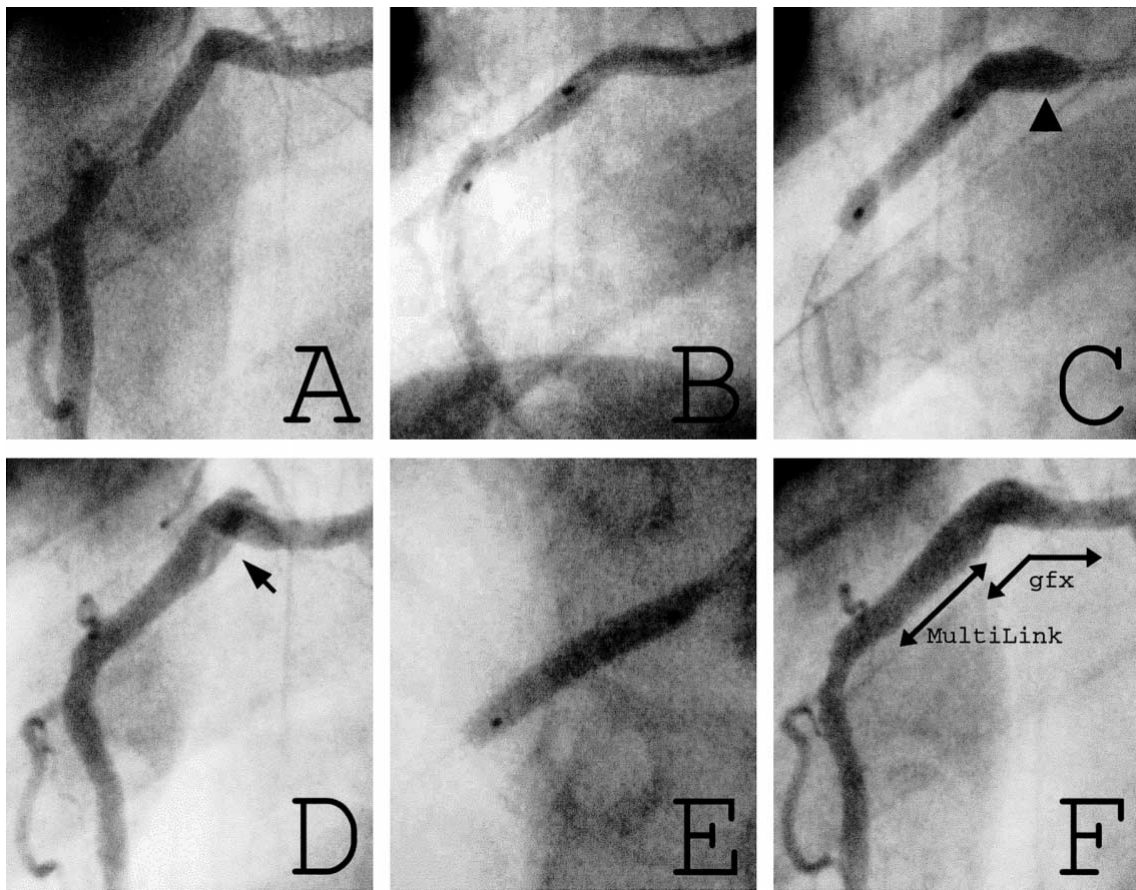

Fig 1. (A) Right coronary angiography showing high grade stenosis (minimal lumen diameter: $0.32 \mathrm{~mm}$, reference: 3.52 $\mathrm{mm}$ ) of the right coronary artery in the left anterior oblique projection. (B) Multi-Link stent is positioned using the delivery system. (C) Right coronary angiography showed overdilatation of the proximal portion of the balloon catheter (overdilated portion: $4.94 \mathrm{~mm}$, mid-portion: $3.23 \mathrm{~mm}$ ) (arrowhead), which resulted in coronary dissection (arrow) (D). (E) A gfx stent was deployed to treat the dissection. (F) The final angiogram showed a good result. high compliance and provides tight adhesion between the stent and balloon catheter, which prevents dislodgment of the stent from the balloon catheter. Furthermore, this membrane promotes even stent expansion! A complication associated with the membrane has been reported ${ }^{4}$; a MultiLink stent premounted on the delivery system was used to treat a dissection after percutaneous transluminal coronary angioplasty. Post stent deployment, detachment of the elastic membrane from the balloon catheter occurred and resulted in embolization of the membrane in the coronary artery. It was assumed that the proximal end of the elastic membrane had been caught on the edge of the guiding catheter during withdrawal. Therefore, the stent manufacturer was compelled to correct this problem by placing the proximal end of the membrane into the shaft of the balloon catheter4

There have been 5 cases of overdilatation of the elastic membrane in Japan (personal communication, Guidant, August 5, 1999). Various reports exist regarding the consequences of balloon rupture. It has been either a benign event5 or, conversely, a potentially catastrophic occurrence resulting in coronary dissection and rupture ${ }^{6-8}$ There are a number of factors, such as the use of high inflation pressure and calcification in the lesion, that may predispose to balloon rupture.6,7 In the present case the cause of balloon rupture was unclear. However, because the rupture occurred at a relatively low pressure with an apparent lack of coronary artery calcification, and the elastic membrane was overdilated, it may be assumed that balloon rupture was due to an intrinsic problem of the balloon catheter. Although the distal end of the elastic membrane is free, the tight adhesion between the stent and balloon catheter might create a contained leak if balloon rupture occurs. This, in turn, might result in overdilatation of the membrane, because of the high compliance, and subsequently result in coronary dissection and possible coronary rupture. Careful observation during balloon inflation for stent deployment should be practiced when utilizing the Multi-Link stent with this delivery system.

\section{References}

1. Carrozza JP Jr, Hermiller JB Jr, Linnemeier TJ, Popma JJ, Yock PG, Roubin GS, et al: Quantitative coronary angiographic and intravascular ultrasound assessment of a new nonarticulated stent: Report from the Guidants MultiLink stent pilot study. J Am Coll Cardiol 1998; 31: 50-56

2. Serruys PW, van der Giessen W, Garcia E, Macaya C, Colombo A, Rutsch W, et al: Clinical and angiographic results with the MultiLink stent implanted under intravascular ultrasound guidance (West2 study). J Invas Cardiol 1998; 10(Suppl B): 20B - 27B

3. Fischman D, Leon MB, Baim DS, Schatz RA, Savage MP, Penn I, et al: A randomized comparison of coronary stent placement and balloon angioplasty in the treatment of coronary artery disease. $N$ Engl J Med 1994; 331: 496-501

4. Benit E, Rocha P, Stroobants D, Jaspers L, Put P, Vijgen J: Coronary embolization of the membrane fixing a 'Multilink' stent to its delivery balloon. Cathet Cardiovasc Diagn 1998; 43: 68-70

5. Simpendorfer CC, Dimas AP, Zaidi A, Hollman J, Franco I, Knezinek V, et al: Balloon rupture during coronary angioplasty. Angiology 1986; 37: 828-831

6. Rothschild R, Voda J: Coronary artery dissection caused by angioplasty balloon rupture. Cathet Cardiovasc Diagn 1990; 19: 26-29

7. LeMay MR, Beanlands DS: Pinhole balloon rupture during coronary angioplasty causing rupture of the coronary artery. Cathet Cardiovasc Diagn 1990; 19: $91-92$

8. De Gregorio J, Goldberg S, Kobayashi N, Kobayashi Y, Vaghetti M, Colombo A: Coronary artery perforation: incidence, cause and outcome (abstract). Circulation 1998; 98: I-21 